\title{
Intuitionistic Fuzzy Logic Control for Washing Machines
}

\author{
Muhammad Akram*, Shaista Habib and Imran Javed \\ Punjab University College of Information Technology, \\ University of the Punjab, Old Campus, Lahore-54000, Pakistan; \\ m.akram@pucit.edu.pk, h.shaista@gmail.com, imranj@pucit.edu.pk
}

\section{Abstract}

In this paper, we describe the development of an intuitionistic fuzzy logic controller for washing machine on the basis of intuitionistic fuzzy systems. Intuitionistic fuzzy inference systems and defuzzification techniques are used to obtain crisp output (i.e., wash time of the washing machine) from an intuitionistic fuzzy input (i.e., type of dirt and degree of dirt). The wash time is calculated using intuitionistic fuzzy rules applied to an inference engine using defuzzification methods.

Keywords:Defuzzification, Intuitionistic Fuzzy Logic, Intuitionistic Fuzzy Logic Controller, Intuitionistic Fuzzy Sets Mathematics Subject Classification: $93 \mathrm{C} 42$

\section{Introduction}

The purpose of control is to influence the behavior of a system by changing one or more inputs to the system according to a set of rules that model the operation of the system. The system may be mechanical, electrical, chemical or any combination of these. Classic control theory uses a mathematical model to define a relationship that transforms the desired (requested) state and the observed (measured) state of the system into one or more inputs that alter the future state of the system. Fuzzy controllers are used to control consumer products, including washing machines, video cameras, and rice cookers, as well as industrial processes, including cement kilns, underground trains, and robots. Fuzzy control is a control method based on fuzzy logic. Just as fuzzy logic can be described simply as computing with words rather than numbers, fuzzy control can be described simply as control with sentences rather than equations. A fuzzy controller can include empirical rules, and that is especially useful in operator-controlled plants. Most frequently used fuzzy logic controllers are: Mamdani (linguistic) controller usually used as a direct closed-loop controller and Takagi-Sugeno controller typically used as a supervisory controller.
Presently, science and technology are featured with complex processes and phenomena for which complete and precise information is not always available. For such cases, mathematical models are developed to handle the type of systems containing elements of uncertainty. A large number of these models are based on an extension of the ordinary set theory, namely, fuzzy set theory. Zadeh ${ }^{18}$ introduced the notion of fuzzy sets as a method of representing uncertainty and vagueness. Since then, the theory of fuzzy sets has become a vigorous area of research in different disciplines, including medical and life sciences, management sciences, social sciences, engineering, statistics, graph theory, artificial intelligence, signal processing, multi-agent systems, pattern recognition, robotics, computer networks, expert systems, decision making and automata theory.

In 1983, Atanassov ${ }^{6}$ introduced the concept of intuitionistic fuzzy sets as a generalization of fuzzy sets. He added in the definition of fuzzy set a new component that determines the degree of non-membership. Fuzzy sets give the degree of membership of an element in a given set; the non-membership of degree equals one minus the degree of membership. Intuitionistic fuzzy sets, which are higher order fuzzy sets, give both a degree of membership

${ }^{*}$ Author for correspondence 
and a degree of nonmembership, which are more-or-less independent of each other; the only requirement is that the sum of these two degrees is not greater than 1 . Application of higher order fuzzy sets makes the solution-procedure more complex, but if the complexity of computationtime, computation volume and memory-space are not of concern then we can achieve better results. Agarwal et al. ${ }^{2}$ presented the design of a probabilistic intuitionistic fuzzy rule based controller. Akram et al. ${ }^{4}$ describes intuitionistic fuzzy logic control for heater fans. Agarwal ${ }^{1}$ describes the development of a fuzzy logic controller for washing machines. In this paper, we present the design of an intuitionistic fuzzy logic controller for washing machines on the basis of intuitionistic fuzzy systems. Intuitionistic fuzzy inference systems and defuzzification techniques are used to obtain crisp output (i.e., wash time) from an intuitionistic fuzzy input (i.e., type of dirt and degree of dirt). The wash time is calculated using intuitionistic fuzzy rules applied in an inference engine using defuzzification methods. We use standard definitions and terminologies in this paper. For notations, terminologies and applications that are not mentioned in the paper, the readers can refer $^{3,5,7,10,11,12,14-24 .}$

\section{Preliminaries}

In this section, we review some elementary concepts whose understanding is necessary fully benefit from this paper.

Definition 2.1: $:^{6}$ An Intuitionistic Fuzzy Set $A$ in $X$ is defined as an object of the form $\mathrm{A}=\left\{\left\langle\mathrm{x}, \mu_{\mathrm{A}}(\mathrm{x}), v_{\mathrm{A}}(\mathrm{x})\right\rangle\right.$ : $\mathrm{x} \in \mathrm{X}\}$ where the functions $\mu_{\mathrm{A}}: \mathrm{X} \rightarrow[0,1]$ and $\nu_{\mathrm{A}}: \mathrm{X} \rightarrow$ $[0,1]$ define the degree of membership and the degree of non-membership of the element $\mathrm{x} \in \mathrm{X}$, respectively, and for every $\mathrm{x} \in \mathrm{X}$ in $\mathrm{A}, 0 \leq \mu_{\mathrm{A}}(\mathrm{x})+v_{\mathrm{A}}(\mathrm{x}) \leq 1$ holds.

Definition 2.2: ${ }^{6}$ For every common fuzzy subset A on $\mathrm{X}$, intuitionistic fuzzy index of $\mathrm{x}$ in $\mathrm{A}$ is defined as $\pi_{A}(\mathrm{x})=$ $1-\mu_{A}(x)-v_{A}(x)$. It is also known as degree of hesitancy or degree of uncertainty of the element $\mathrm{x}$ in A. Obviously, for every $\mathrm{x} \in \mathrm{X}, 0 \leq \pi_{\mathrm{A}}(\mathrm{x}) \leq 1$.

Definition 2.3: $:^{9}$ An intuitionistic fuzzy number (IFN) $\mathrm{A}^{\sim \mathrm{I}}$ is

- an intuitionistic fuzzy subset of the real line,

- normal, that is, there is some $\mathrm{x}_{0} \in \mathrm{R}$ such that $\mu_{\mathrm{A}^{-I}}$ $\left(\mathrm{x}_{0}\right)=1, v_{\mathrm{A} \cdot \mathrm{I}}\left(\mathrm{x}_{0}\right)=0$,
- convex for the membership function $\mu_{\mathrm{A}^{-1}}(\mathrm{x})$, that is, $\mu_{\mathrm{A}^{\top} \mathrm{I}}\left(\lambda \mathrm{x}_{1}+(1-\lambda) \mathrm{x}_{2}\right) \geq \min \left(\mu_{\mathrm{A}^{-\top} \mathrm{I}}\left(\mathrm{x}_{1}\right), \mu_{\mathrm{A}^{-\top} \mathrm{I}}\left(\mathrm{x}_{2}\right)\right)$ for every $\mathrm{x}_{1}, \mathrm{x}_{2} \in \mathrm{R}, \lambda \in[0,1]$,

- concave for the non-membership function $v_{\mathrm{A}^{-I}}(\mathrm{x})$, that is, $v_{\mathrm{A}^{-I}}\left(\lambda \mathrm{x}_{1}+(1-\lambda) \mathrm{x}_{2}\right) \leq \max \left(v_{\mathrm{A}^{-\top} \mathrm{I}}\left(\mathrm{x}_{1}\right), v_{\mathrm{A}^{-I}}\left(\mathrm{x}_{2}\right)\right)$ for every $\mathrm{x}_{1}, \mathrm{x}_{2} \in \mathrm{R}, \lambda \in[0,1]$.

Definition 2.4: $:^{9}$ A triangular intuitionistic fuzzy number (TriIFN) $\mathrm{A}^{\sim \mathrm{I}}$ is an intuitionistic fuzzy set in $\mathrm{R}$ with membership function and non-membership function as follows:

and where $a \in R, \alpha, \beta, \alpha^{\prime}, \beta^{\prime} \geq 0$ such that $\alpha \geq \alpha^{\prime}$ and $\beta \leq \beta^{\prime}$.

The symbolic representation of TriIFN is $\mathrm{A}^{\sim} \mathrm{I}_{\text {TrifFN }}=$ [a; $\alpha, \beta ; \alpha^{\prime}, \beta^{\prime}$ ]. Here $\alpha$ and $\beta$ are called left and right spreads of membership function $\mu_{A^{\prime} \mathrm{T}}(\mathrm{x})$, respectively. $\alpha^{\prime}$ and $\beta^{\prime}$ represent left and right spreads of non-membership function $v_{\mathrm{A}^{\circ \mathrm{I}}}(\mathrm{x})$, respectively.

Definition 2.5: ${ }^{8}$ The support of an intuitionistic fuzzy set $\mathrm{A}^{\sim} \mathrm{I}$ on $\mathrm{R}$ is the crisp set of all $\mathrm{x} \in \mathrm{R}$ such that $\mu_{\mathrm{A}^{-1}}(\mathrm{x})>$ $0, v_{\mathrm{A}^{-I} \mathrm{I}}(\mathrm{x})>0$ and $\mu_{\mathrm{A}^{-I} \mathrm{I}}(\mathrm{x})+v_{\mathrm{A}^{-\top} \mathrm{I}}(\mathrm{x}) \leq 1$.

Definition 2.6: An intuitionistic fuzzy set $A=\{<x, \mu A$ $\left.(\mathrm{x}), \_\mathrm{A}(\mathrm{x})>/ \mathrm{x} \in \mathrm{X}\right\}$ is called intuitionistic fuzzy normal if there exist at least two points $\mathrm{x}_{0}, \mathrm{x}_{1} \in \mathrm{X}$ such that $\mu_{\mathrm{A}}\left(\mathrm{x}_{0}\right)=1$, $v_{A}\left(x_{1}\right)=1$. Therefore, a given intuitionistic fuzzy set $A$ is intuitionistic fuzzy normal if there is at least one point that surely belongs to A and at least one point which do not belong to A.

For each proposition (in the classical sense), one can assign its truth value: truth - denoted byl, or falsity - 0. In the case of fuzzy logics this truth value is a real number in the interval $[0,1]$ and can be called "truth degree" of a particular proposition. In an intuitionistic fuzzy logic, Atanassov and Gargov" added one more value - "falsity degree" - which is in the interval $[0,1]$ as well. Thus, one assigns to the proposition $\mathrm{p}$ two real numbers $\mu_{\mathrm{p}}$ and $\nu_{\mathrm{p}}$ with the following constraint to hold:

$$
\left[\mu_{\mathrm{p}}+v_{\mathrm{p}} \leq 1\right]
$$

Let $\mathrm{p}=\left(\mu_{\mathrm{p}}, v_{\mathrm{p}}\right)$ and $\mathrm{q}=\left(\mu_{\mathrm{q}}, v_{\mathrm{q}}\right)$ be two intuitionistic fuzzy propositions, then

- $\mathrm{p}=\left(\max \left(\mu_{\mathrm{p}}, \mu_{\mathrm{q}}\right), \min \left(\nu_{\mathrm{p}}, v_{\mathrm{q}}\right)\right)$

- $\mathrm{p}=\left(\min \left(\mu_{\mathrm{p}}, \mu_{\mathrm{q}}\right), \max \left(v_{\mathrm{p}}, v_{\mathrm{q}}\right)\right)$

- $\sim p=\left(v_{p}, \mu_{p}\right)$

- $\mathrm{p} \rightarrow \mathrm{q}=\left(\max \left(v_{\mathrm{p}}, \mu_{\mathrm{q}}\right), \min \left(\mu_{\mathrm{p}}, v_{\mathrm{q}}\right)\right)$ 


\section{Basic Structure of the Proposed Model}

The basic structure of the intuitionistic fuzzy controller for washing machine is shown in Figure 1. Intuitionistic fuzzy inference system takes two inputs that are type-ofdirt and degree-of-dirt. The input values passed through proposed controller and wash time determine.

\section{General Procedure for Intuitionistic Fuzzy Controller}

We conclude that the procedure for implementing the intuitionistic fuzzy techniques to control systems consists of the following stages:

- Linguistic variables: Establishing the controller's input variables (type-of-dirt, degree-of-dirt) and output variable (wash time).

- Defining the fuzzification, inference and defuzzification mechanisms.

- Fuzzification: Assigning the precise values to the intuitionistic fuzzy input sets and calculating the degree of membership and non-membership for each of those sets.

- Inference: Applying the intuitionistic fuzzy logic rules and calculating the output fuzzy sets inferred from the input sets

- Defuzzification: Calculating the precise output value (wash time) from the inferred fuzzy sets. These precise values will be the controller's outputs (commands) and be applied to the system to be controlled.

\section{The Proposed Intuitionistic Fuzzy Inference System}

The system consists of the following units:

- intuitionistic fuzzifer

- intuitionistic fuzzy inference engine

- intuitionistic defuzzifer

We proposes intuitionistic fuzzy controller for washing machine. Controller takes two inputs: type-of-dirt and degree-of-dirt, and wash time consider as an output of the controller. To determine type-of-dirt and degree-of-dirt, sensor used and wash time determine using sensor reading. To convert crisp values into linguistic values intuitionistic fuzzifier is used against each input. Rules are manipulated in intuitionistic fuzzy inference engine. For both inputs range for membership and non-membership is $0-100$. The range is divided into three membership functions. Membership functions of type-of-dirt are: not-greasy (0-50), medium $(0-100)$ and greasy (50-100). Membership functions of degree-of-dirt are: small (0-50), medium (0-100) and large (50-100). Non-membership functions of type-of-dirt are: not-greasy (0-55), medium (0-100) and greasy (45-100). Non-membership functions of degree-of-dirt are: small $(0-55)$, medium (0-100) and large (45-100). The functional definition of these intuitionistic fuzzy sets/profiles as triangular intuitionistic fuzzy numbers is shown in Figures 2, 3, 4 , and 5. The membership and non-membership functions for type-of-dirt and degree-of-dirt are given mathematically as below:

For wash time five intuitionistic triangular fuzzy membership functions are used. The range of the wash time

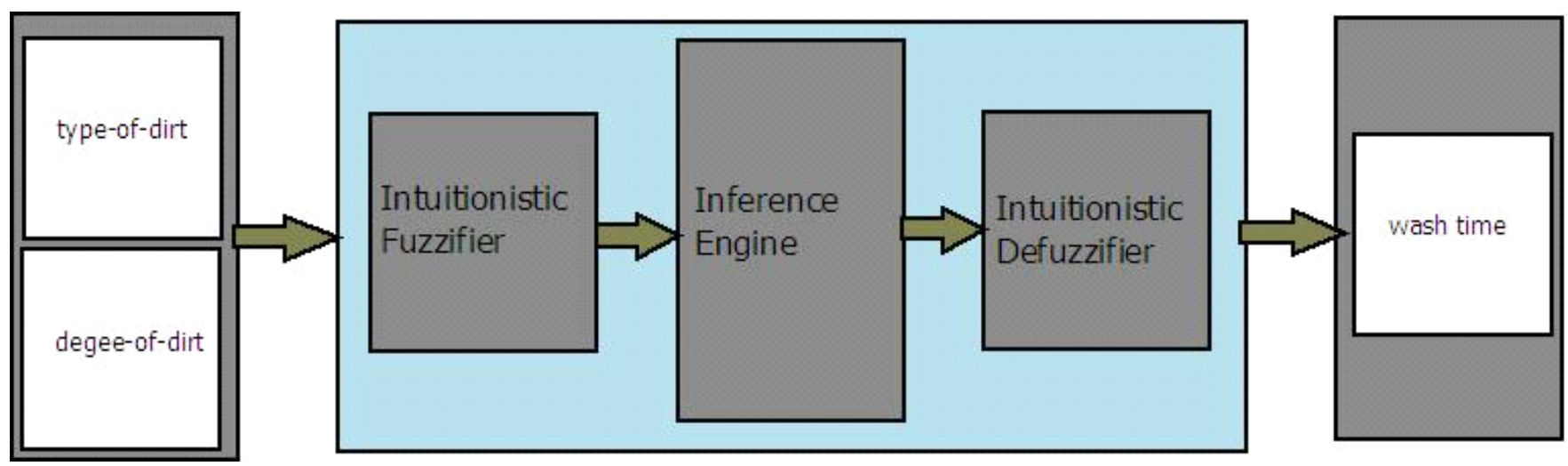

Figure 1. Block diagram of Intuitionistic fuzzy controller of washing machine. 


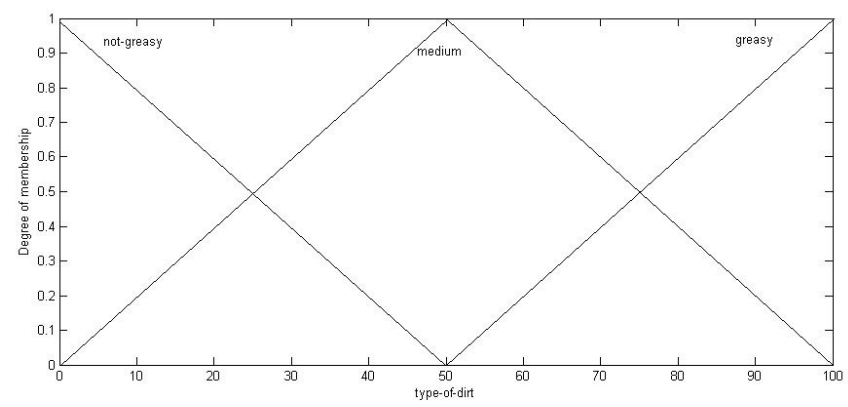

Figure 2. Membership functions for type-of-dirt.

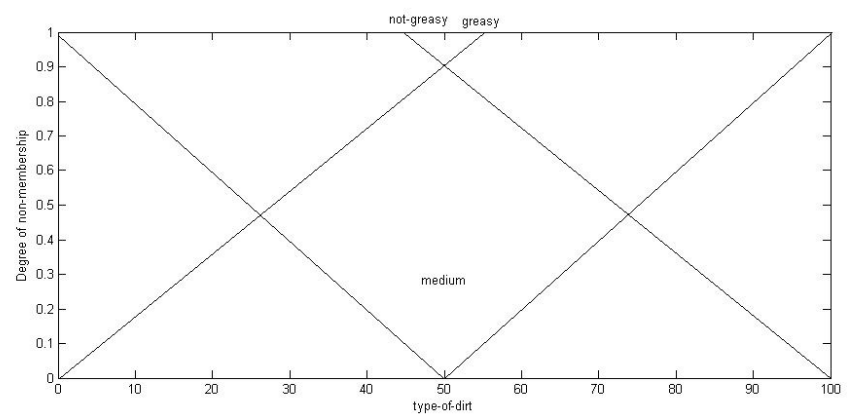

Figure 3. Non-Membership functions for type-of-dirt.

is 0-60 minutes. Membership functions of wash time are: very-short (0-12), short (8-20), medium (12-40), long $(20-60)$ and very-long (40-60). These profiles are shown in Figures 6 and 7. We have added $\alpha=5$ and $\beta=5$ to the corresponding membership functions. Membership and non-membership functions for wash time can be express mathematically. The corresponding membership and non-membership functions for fan speed are given mathematically below:

In order to explain the working of this intuitionistic controller we take an example value and execute all blocks of controller. Let sensor reading for type-of-dirt and degree-of-dirt are 80 and 90 respectively. Now we fuzzify these values using membership and non-membership functions of both inputs. We get the following fuzzified values:

$$
\begin{aligned}
& \mu_{\text {not - greasy }}(\mathrm{x})=0 \\
& \mu_{\text {medium }}(\mathrm{x})=0.4 \\
& \mu_{\text {greasy }}(\mathrm{x})=0.6 \\
& \mu_{\text {type }- \text { of }- \text { dirt }}=\{0,0.4,0.6\} \\
& \mu_{\text {small }}(\mathrm{x})=0 \\
& \mu_{\text {medium }}(\mathrm{x})=0.2 \\
& \mu_{\text {large }}(\mathrm{x})=0.8
\end{aligned}
$$

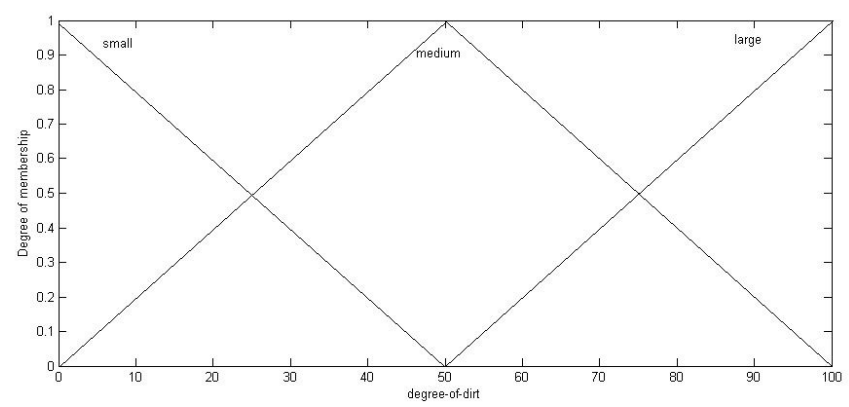

Figure 4. Membership functions for degree-of-dirt.

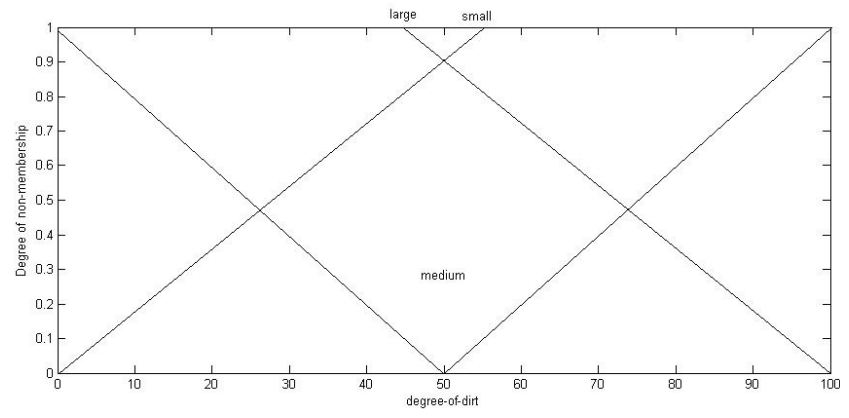

Figure 5. Non-Membership functions for degree-of-dirt.

$\mu_{\text {degree - of - dirt }}=\{0,0.2,0.8\}$.

$v_{\text {not - greasy }}(\mathrm{x})=1$

$v_{\text {medium }}(\mathrm{x})=0.6$

$v_{\text {greasy }}(\mathrm{x})=0.36$

$v_{\text {type - of - dirt }}=\{1,0.6,0.36\}$

$v_{\text {small }}(\mathrm{x})=1$

$v_{\text {medium }}(\mathrm{x})=0.8$

$v_{\text {large }}(\mathrm{x})=0.18$

$v_{\text {degree - of - dirt }}=\{1,0.8,0.18\}$

\section{Intuitionistic Fuzzy Inference Engine}

Intuitionistic fuzzy inference engine gives human like reasoning which are express by rules. Rules are IF-Then statements. We use same rules of old fuzzy logic controller of washing machine which are as follows:

Rule 1: if type-of-dirt is greasy and degree-of-dirt is large then wash time is very-long

Rule 2: if type-of-dirt is greasy and degree-of-dirt is medium then wash time is long

Rule 3: if type-of-dirt is greasy and degree-of-dirt is small then wash time is long 


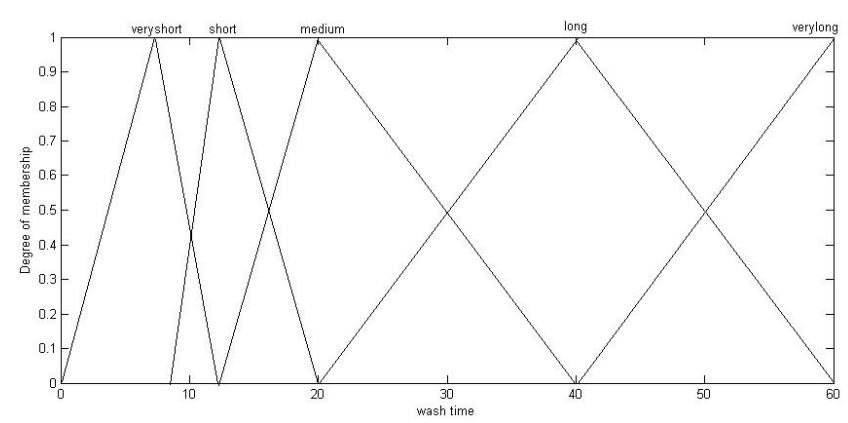

Figure 6. Membership functions for wash time.

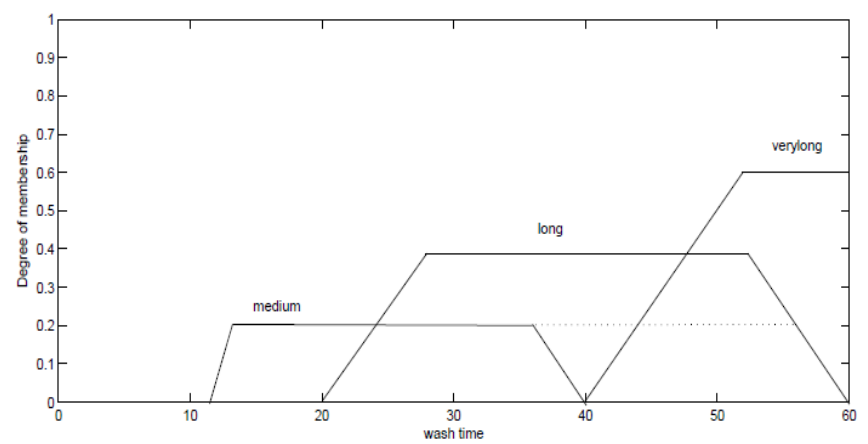

Figure 7. Combined profile of membership of medium, long and very long.

Rule 4: if type-of-dirt is medium and degree-of-dirt is large then wash time is long

Rule 5: if type-of-dirt is medium and degree-of-dirt is medium then wash time is medium

Rule 6: if type-of-dirt is medium and degree-of-dirt is small wash time is medium

Rule 7: if type-of-dirt is not-greasy and degree-of-dirt is large then wash time is medium

Rule 8: if type-of-dirt is not-greasy and degree-of-dirt is medium then wash time is short

Rule 9: if type-of-dirt is not-greasy and degree-of-Dirt is small then wash time is very-short

Now we actually go through the actual working of the inference process. In case of membership:

medium $=0.4=0.2$

medium $=0.4=0.4$

greasy $=0.6=0.2$

greasy $=0.6=0.6$

Membership fires rule 5, 4, 2 and 1 respectively.

In case of non-membership:

medium $=0.6=0.8$

medium $=0.6=0.6$ greasy $=0.36=0.8$
greasy $=0.36=0.36$

Non-membership also fires rule 5, 4, 2 and 1 respectively. Now we move towards defuzzification process. According to rule 5 wash time will be medium.

$$
\begin{aligned}
\mu_{\text {medium }}(\mathrm{x}) & = \\
0.2 & = \\
\mathrm{x} & =13.6 \\
\mu_{\text {medium }}(\mathrm{x}) & = \\
0.2 & = \\
\mathrm{x} & =36 \\
v_{\text {medium }}(\mathrm{x}) & = \\
0.8 & = \\
\mathrm{x} & =9.6 \\
v_{\text {medium }}(\mathrm{x}) & = \\
0.8 & = \\
\mathrm{x} & =40
\end{aligned}
$$

According to rule 4 wash time will be long.

$$
\begin{aligned}
\mu_{\text {long }}(\mathrm{x}) & = \\
0.4 & = \\
\mathrm{x} & =28 \\
\mu_{\text {long }}(\mathrm{x}) & = \\
0.4 & = \\
\mathrm{x} & =60 \\
v_{\text {long }}(\mathrm{x}) & = \\
0.6 & = \\
\mathrm{x} & =25 \\
v_{\text {long }}(\mathrm{x}) & = \\
0.6 & = \\
\mathrm{x} & =52
\end{aligned}
$$

According to rule 2 wash times will be long.

$$
\begin{aligned}
\mu_{\text {long }}(\mathrm{x}) & = \\
0.2 & = \\
\mathrm{x} & =24 \\
\mu_{\text {long }}(\mathrm{x}) & = \\
0.2 & = \\
\mathrm{x} & =56 \\
v_{\text {long }}(\mathrm{x}) & = \\
0.8 & = \\
\mathrm{x} & =20 \\
v_{\text {long }}(\mathrm{x}) & = \\
0.8 & = \\
\mathrm{x} & =56
\end{aligned}
$$

According to rule 1 wash time will be very long.

$$
\begin{aligned}
\mu_{\text {very long }}(\mathrm{x}) & = \\
0.6 & = \\
\mathrm{x} & =52 \\
v_{\text {very long }}(\mathrm{x}) & =
\end{aligned}
$$




$$
\begin{aligned}
0.36 & = \\
\mathrm{x} & =51
\end{aligned}
$$

Combined profile of membership and non-membership of medium, long and very long is shown in Figures 8 and 9.

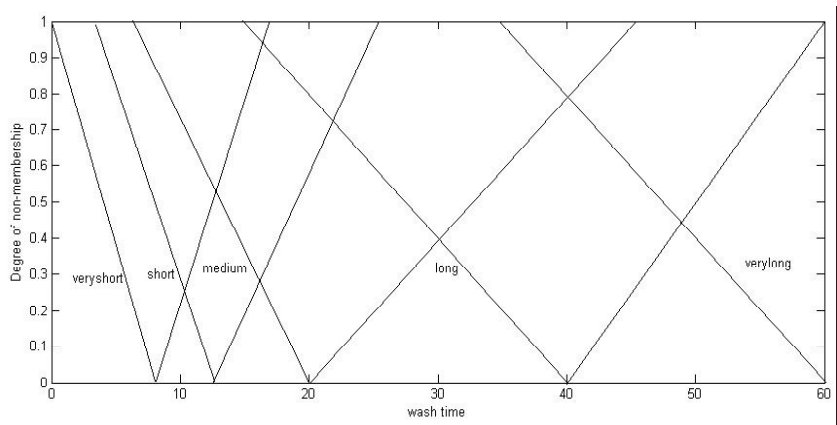

Figure 8: Non-Membership functions for wash time.

\section{Defuzzification}

Finally now we defuzzify linguistic value to crisp value. There are several techniques in the literature through which we can perform defuzzification. We apply Takagi

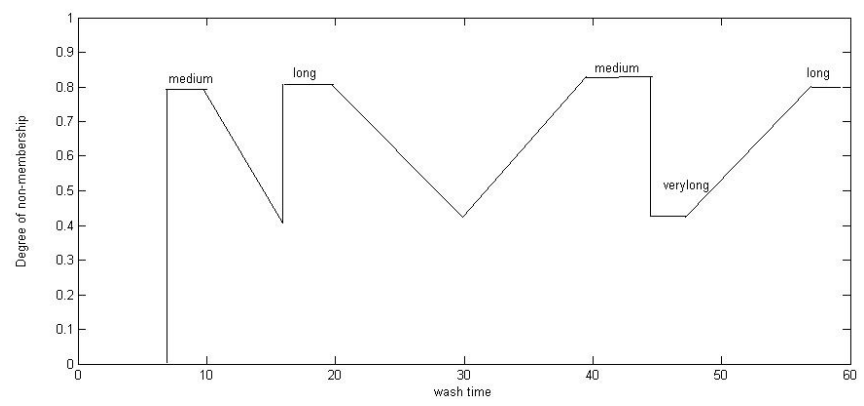

Figure 9. Combined profile of non-membership of medium, long and very long.

Table 1. Defuzzification of medium using TS formula

\begin{tabular}{rlllllll}
\hline $\mathbf{x}$ & $\mu_{x}$ & $\nu_{x}$ & $\pi_{x}$ & $\mathrm{~A}=\left(1-\pi_{x}\right) \mu_{x}$ & $\mathrm{~B}=\pi_{x} \mu_{x}$ & $\mathrm{~A}+\mathrm{B}$ & $\mathrm{x}(\mathrm{A}+\mathrm{B})$ \\
\hline 7 & 0 & 0.8 & 0.2 & 0 & 0 & 0 & 0 \\
12 & 0 & 0.6 & 0.4 & 0 & 0 & 0 & 0 \\
17 & 0.2 & 0.23 & 0.57 & 0.086 & 0.114 & 0.2 & 3.4 \\
22 & 0.2 & 0.08 & 0.72 & 0.056 & 0.144 & 0.2 & 4.4 \\
27 & 0.2 & 0.28 & 0.52 & 0.096 & 0.104 & 0.2 & 5.4 \\
32 & 0.2 & 0.48 & 0.32 & 0.136 & 0.064 & 0.2 & 6.4 \\
37 & 0.15 & 0.68 & 0.17 & 0.1245 & 0.0255 & 0.15 & 5.55 \\
42 & 0 & 0.8 & 0.2 & 0 & 0 & 0 & 0 \\
45 & 0 & 0.8 & 0.2 & 0 & 0 & 0 & 0 \\
& & & & & & 0.95 & 25.15 \\
\hline
\end{tabular}

Result for medium is $=$

Table 2. Membership and Nonmembershipvalues of long (according to rule 4)

\begin{tabular}{lll}
\hline $\mathbf{x}$ & $\boldsymbol{\mu}_{\mathrm{x}}$ & $\boldsymbol{v}_{\mathrm{x}}$ \\
\hline 15 & 0 & 0.6 \\
20 & 0 & 0.6 \\
25 & 0.25 & 0.6 \\
30 & 0.4 & 0.4 \\
35 & 0.4 & 0.2 \\
40 & 0.4 & 0 \\
45 & 0.4 & 0.25 \\
50 & 0.4 & 0.5 \\
55 & 0.25 & 0.6 \\
60 & 0 & 0.6 \\
\hline
\end{tabular}


Sugani formula ${ }^{13}$ for defuzzification. Takagi Sugani’s formula is:

$$
\mathrm{x}=
$$

where

$$
\begin{aligned}
& \mu_{A}{ }^{j}= \\
& v_{A}{ }^{j}= \\
& \pi_{A}{ }^{j}=1-\mu_{A}{ }^{j}-v_{A}{ }^{j}
\end{aligned}
$$

From TS take min of membership and max of non-membership then Table 1 and Table 5 formulates defuzzification of medium and very long using TS formula. Table 2 and 3 determines membership and nonmembership values according to rule 4 and 2 , respectively. formulate for long.

Thus we conclude that wash time is 38.99 minutes which is average of 26.47, 39.2 and 51.3.

\section{Conclusions}

Intuitionistic fuzzy logic control is a methodology bridging artificial intelligence and traditional control theory.
This methodology is usually applied in only those cases where accuracy is not of high importance. By using intuitionistic fuzzy logic control, we have been able to obtain wash time of a washing machine. In other words, the situation analysis ability has been incorporated in the washing machine that makes the washing machine much more

Table 3. Membership and Non-membership values of long (according to rule 2)

\begin{tabular}{lcc}
\hline $\mathbf{x}$ & $\mu_{\mathrm{x}}$ & $\boldsymbol{\nu}_{\mathrm{x}}$ \\
\hline 15 & 0 & 0.8 \\
20 & 0 & 0.8 \\
25 & 0.2 & 0.6 \\
30 & 0.2 & 0.4 \\
35 & 0.2 & 0.2 \\
40 & 0.2 & 0 \\
45 & 0.2 & 0.25 \\
50 & 0.2 & 0.5 \\
55 & 0.2 & 0.75 \\
60 & 0 & 0.8 \\
\hline
\end{tabular}

Table 4. Defuzzification of long using TS formula

\begin{tabular}{llllcllc}
\hline $\mathbf{x}$ & $\boldsymbol{\mu}_{\mathrm{x}}$ & $\boldsymbol{v}_{\mathrm{x}}$ & $\pi_{\mathrm{x}}$ & $\mathrm{A}=\left(\mathbf{1}-\pi_{\mathrm{x}}\right) \boldsymbol{\mu}_{\mathrm{x}}$ & $\mathrm{B}=\pi_{\mathrm{x}} \boldsymbol{\mu}_{\mathrm{x}}$ & $\mathrm{A}+\mathrm{B}$ & $\mathrm{x}(\mathrm{A}+\mathrm{B})$ \\
\hline 15 & 0 & 0.8 & 0.2 & 0 & 0 & 0 & 0 \\
20 & 0 & 0.8 & 0.2 & 0 & 0 & 0 & 0 \\
25 & 0.2 & 0.6 & 0.2 & 0.16 & 0.04 & 0.2 & 5 \\
30 & 0.2 & 0.4 & 0.4 & 0.12 & 0.08 & 0.2 & 6 \\
35 & 0.2 & 0.2 & 0.6 & 0.08 & 0.12 & 0.2 & 7 \\
40 & 0.2 & 0 & 0.8 & 0.04 & 0.16 & 0.2 & 8 \\
45 & 0.2 & 0.25 & 0.55 & 0.09 & 0.11 & 0.0099 & 0.405 \\
50 & 0.2 & 0.5 & 0.3 & 0.14 & 0.06 & 0.2 & 10 \\
55 & 0.2 & 0.75 & 0.05 & 0.19 & 0.01 & 0.2 & 11 \\
60 & 0 & 0.8 & 0.2 & 0 & 0 & 0 & 0 \\
& & & & & & 1.2099 & 47.405 \\
\hline
\end{tabular}

Result for long is $=39.2$

Table 5. Defuzzification of very long using TS formula

\begin{tabular}{lllllllc}
\hline $\mathbf{x}$ & $\mu_{\mathrm{x}}$ & $\nu_{\mathrm{x}}$ & $\pi_{\mathrm{x}}$ & $\mathrm{A}=\left(1-\pi_{\mathrm{x}}\right) \mu_{\mathrm{x}}$ & $\mathrm{B}=\pi_{\mathrm{x}} \mu_{\mathrm{x}}$ & $\mathrm{A}+\mathrm{B}$ & $\mathrm{x}(\mathrm{A}+\mathrm{B})$ \\
\hline 35 & 0 & 0.36 & 0.64 & 0 & 0 & 0 & 0 \\
40 & 0 & 0.36 & 0.64 & 0 & 0 & 0 & 0 \\
45 & 0.25 & 0.36 & 0.39 & 0.1525 & 0.0975 & 0.25 & 11.25 \\
50 & 0.5 & 0.36 & 0.14 & 0.43 & 0.07 & 0.5 & 25 \\
55 & 0.6 & 0.2 & 0.2 & 0.48 & 0.12 & 0.6 & 33 \\
60 & 0 & 0 & 0.1 & 0 & 0 & 0 & 0 \\
& & & & & & 1.35 & 69.25 \\
\hline
\end{tabular}

Result for very long is $=51.3$. 
automatic compare to those that use simple fuzzy logic or the traditional control system design methodology.

\section{Acknowledgement}

The authors are thankful to the referees for their valuable comments and suggestions.

\section{References}

1. Agarwal M. Fuzzy logic control of washing machines. Indian Institute of Technology, Kharagpur; 2010.

2. Agarwal M, Biswas KK, Hanmandlu M. Probabilistic intuitionistic fuzzy rule based controller. ICARA. 2011; 214-219.

3. Alcal'a R, Casillas J, Cord'on O, Gonz'alez A, Herrera F. A genetic rule weighting and selection process for fuzzy control of heating, ventilating and air conditioning systems. Eng Appl Artif Intell. 2005; 18; 279-296.

4. Akram M, Shahzad S, Butt A, Khaliq K. Intuitionistic fuzzy logic control for heater fans, Mathematics in Computer Science. 2013; 7(3):367-78.

5. Angelov P. Crispification: defuzzification over intuitionistic fuzzy sets. Bulletin for Studies and Exchanges on Fuzziness and its Applications, BUSEFAL. 1995; 64:51-55.

6. Atanassov KT. Intuitionistic fuzzy sets, VII ITKR's Session, Sofia. 1983 Jun. Deposed in Central Sci-Techn. Library of Bulg Acad of Sci. 1697/84 (in Bulgarian).

7. Atanassov KT, Gargov G. Elements of intuitionistic fuzzy logic. Part I, Fuzzy Sets and Systems. 1998; 95(1):39-52.

8. Atanassov KT. Intuitionistic fuzzy sets: Theory and applications, Studies in fuzziness and soft computing, Heidelberg, New York, Physica-Verl; 2012.

9. Ban AI. Nearest interval approximation of an intuitionistic fuzzy number. In Reusch B, editor. Computational Intelligence, Theory and Applications. 2006; 229-40.

10. Chen SJ, Hwang CL. Fuzzy multiple attribute decision making. Berlin Heildelberg, New York: Springer Verlag; 1992.

11. Ganesh M. Introduction to fuzzy sets and fuzzy logic. Prentice Hall of India, 2006.
12. A.N. Isizoh, S.O. Okide, A.E. Anazia and C.D. Ogu, Temperature control system using fuzzy logic technique. International Journal of Advanced Research in Artificial Intelligence. 2012; 1(3); 27-31.

13. Lin Y, Zhou X, Gu S, Wang S. The Takagi-Sugeno intuitionistic fuzzy systems are universal approximators. 2012 2nd International Conference on Consumer Electronics, Communications and Networks.

14. Parvathi R, Malathi C, Akram M, Atanassov KT. Intuitionistic fuzzy linear regression analysis. Fuzzy Optim Decis Making. 2013; 12:215-29.

15. Pedrycz W. Fuzzy control and fuzzy systems, Research Studies. New York: Press/John Wiley; 1993.

16. Su X, Shi P, Wu L, Song Y-D. A novel control design on discrete-time Takagi-Sugeno fuzzy systems with timevarying delays. IEEE Trans Fuzzy Syst. DOI:10.1109/ TFUZZ.2012.2226941.

17. Su X, Shi P, Wu L, Song Y-D. A novel approach to filter design for T-S fuzzy discrete time systems with time-varying delay. IEEE Trans Fuzzy Syst; 2012; 20(6):1114-29.

18. Zadeh LA. Fuzzy sets. Information and Control. 1965; 8:338-53.

19. Zadeh LA. The concept of linguistic variable and its applicationtoapproximatereasoningI.InformationSciences.1975; 8:199-249.

20. Zadeh LA. The concept of linguistic variable and its application to approximate reasoning II. Information Sciences. 1976; 8:310-57.

21. Zimmermann H-J. Fuzzy set theory and its applications. Springer; 2012.

22. Zou L, Liu X, Ruan D, Xu Y. Linguistic truth-valued intuitionistic fuzzy algebra. Multiple-Valued Logic and Soft Computing. 2012; 18(5-6):445-56.

23. Zou L, Li W, Xu Y. Six-element linguistic truth-valued intuitionistic reasoning in decision making, ISNN. 25008; (1):266-74.

24. Iancu I, Gabroveanu M, Cosulschi M. Intuitionistic fuzzy control based on association rules. Computational Collective Intelligence Technologies and Applications Lecture Notes in Computer Science. 2013; 8083: 235-44. 